\title{
miR-223 and miR-142 attenuate hematopoietic cell proliferation, and miR-223 positively regulates miR-142 through LMO2 isoforms and CEBP- $\beta$
}

\author{
Wei Sun ${ }^{1}$, Wenwen Shen ${ }^{1}$, Shuang Yang ${ }^{1}$, Fen $\mathrm{Hu}^{1}$, Huihui $\mathrm{Li}^{1}$, Tian-Hui Zhu \\ ${ }^{1}$ Laboratory of Molecular Genetics, College of Medicine, Nankai University, Tianjin 300071, China
}

\begin{abstract}
miR-142 and miR-223 have been identified as hematopoietic specific microRNAs. miR-223 has crucial functions in myeloid lineage development. However, the function of miR-142 remains unclear. In this study, we found that both miR-142 and miR-223 attenuated the proliferation of hematopoietic cells, and that miR-223 up-regulated miR-142 expression through the LMO2-L/-S isoforms and CEBP- $\beta$. miR-223 negatively regulated both LMO2-L/-S isoforms and CEBP- $\beta$ post-transcriptionally, while CEBP- $\beta$ positively regulated the LMO2-L/-S isoforms and both of the LMO2-L/-S isoforms negatively regulated miR-142. These results reveal a novel miR-223-CEBP- $-\mathrm{LMO2}-$ miR-142 regulatory pathway, which has pivotal functions in hematopoiesis.
\end{abstract}

Keywords: miR-142; miR-223; LMO2-L; LMO2-S; CEBP- $\beta$; proliferation

Cell Research (2010) 20:1158-1169. doi:10.1038/cr.2010.134; published online 21 September 2010

\section{Introduction}

MicroRNAs are a class of small noncoding RNAs of 19 25 nt (usually $\sim 22 \mathrm{nt}$ ). Their genes can be located separately or in clusters in noncoding regions of the genome or in introns of coding genes [1]. The primary transcripts of most microRNAs (pri-miRNAs) are generated by RNA polymerase II [2], and they have a $5^{\prime}$ cap and a $3^{\prime}$ polyA tail [3]. The pri-miRNAs are then processed by Drosha, an RNase III superfamily member, in the nucleus to form an $80 \sim 100$ nt hairpin precursor. Precursor miRNAs are exported by exportin- 5 and cleaved by Dicer in the cytoplasm, releasing the mature miRNAs [49]. Mature microRNAs usually function by targeting the 3' UTR of mRNAs, which leads to translation inhibition or target degradation [10].

In hematopoiesis, as well as in leukemia, there is increasing evidence that microRNAs have critical functions [11]. Several hematopoietic specific microRNAs, including miR-181, miR-142 and miR-223, were identified by

Correspondence: Tian-Hui Zhu

Tel/Fax: 86-22-23505501

E-mail: zhuth@nankai.edu.cn

Received 4 December 2009; revised 15 March 2010; accepted 11 April 2010; published online 21 September 2010
Chen and his colleagues [12]. They found that after overexpressing miR-142 or miR-223 in Lin hematopoietic progenitors, the percentage of $\mathrm{T}$ cells derived from these progenitor cells increased significantly. Furthermore, Fazi et al. found that miR-223 expression was activated by CEBP- $\alpha$ and inhibited by NFI-A through a competitive binding mechanism. Meanwhile, miR-223 could target NFI-A mRNA and repress its translation, completing a mini regulatory circuit [13]. miR-223 was shown to have crucial functions in promoting granulocytic [14, 15] and suppressing erythrocytic differentiation [16], respectively. Another study showed that the expression of miR-223 was also regulated by the myeloid/erythroidspecific transcriptional regulators PU1 and GATA1, where GATA1 and PU1 functioned as a transcriptional repressor and activator [17], respectively.

LMO 2 and CEBP- $\beta$ are both crucial regulators of hematopoiesis. CEBP- $\beta$ belongs to the family of basic leucine zipper (bZIP) transcription factors, and its main function has been implicated to be in control of myeloid differentiation [18]. Forced expression of CEBP- $\alpha / \beta$ can even re-program committed $\mathrm{B}$ or $\mathrm{T}$ cell progenitors into macrophages $[19,20]$.

The $l m o 2$ gene was first cloned from an acute $\mathrm{T}$ lymphocyte leukemia (T-ALL) patient with an $(11 ; 14)$ (p13;q11) translocation [21], and it was generally consid- 
ered as a proto-oncogene in T cells [22-24]. It was later shown to be expressed in all hematopoietic cells except mature $\mathrm{T}$ lymphocytes, but its expression could be detected in precursor $\mathrm{T}$ cells and it was down-regulated during the double-negative (DN) stage in T-cell development [25]. Transgenic studies showed that $\operatorname{lmo} 2$ mainly functions in early hematopoiesis and embryonic angiogenesis $[26,27]$. A Lmo2 null mutation in mice led to the failure of yolk sac erythropoiesis and subsequent embryonic lethality around E10.5 [28]. In contrast, over-expression of LMO2 caused T-cell development arrest and a T-ALLlike syndrome [29]. This finding was supported by two reported cases of gene therapy for X-SCID, in which the therapeutic lentivirus vector inserted into the LMO2 locus, resulting in abnormal LMO2 expression and TALL syndrome [30]. Interestingly, in T-cell-specific $1 m o 2$ conditional knockout mouse models, the cell-specific deletion of $1 m o 2$ showed no prominent effects on T-cell development [31].

The $l m o 2$ gene encodes two isoforms of protein product, $L M O 2-L$ and $L M O 2-S$ [32, 33]. LMO2-L and -S have their own promoters, and their expressions are stringently regulated in hematopoietic cells [34-36]. Both LMO2-L and -S are transcriptional regulators: they function as bridge molecules to assemble complexes with their partners, including LDB1, GATA1, TAL1 and E47. These complexes regulate gene expression by recognizing and binding to specific DNA sequences of their targets $[37,38]$.

Although there is increasing evidence that miR-142,
miR-223, LMO2 and CEBP have pivotal roles in hematopoiesis, their exact regulatory patterns and functional relationships are still unclear. In this study, we found a similar function for both the LMO2-L and $-\mathrm{S}$ isoforms in down-regulating miR-142 expression. We also found that miR-223 could negatively regulate both LMO2 isoforms transcriptionally and post-transcriptionally, the former of which was mediated by CEBP- $\beta$. Taken together, our data reveal a novel miR-223 - CEBP- $\beta$ - LMO2miR-142 regulatory pathway and suggest that miR-223 achieves its function of arresting hematopoietic cell proliferation by up-regulating the expression of miR-142 through this pathway.

\section{Results}

Over-expression of miR-223 in the myeloid cell line K562 caused up-regulation of miR-142

miR-223 and miR-142 are microRNAs that have prominent effects on hematopoiesis. To further study their functions in detail, K562 cells stably expressing miR-142 (K562 $\left.{ }^{\text {miR-142 }}\right)$ or miR-223 (K562 $\left.{ }^{\text {miR-223 }}\right)$ were generated by G418 selection for 4 weeks after transfection of a miR-142/223 expression vector. Interestingly, when RT-PCR was performed to assess the over-expression status of miR-142 or miR-223 in K562 $2^{\text {miR-142 }}$ and $\mathrm{K} 562^{\text {miR-223 }}$ cells, it was found that in K562 cells that over-expressed miR-223, the expression level of miR-142 was also higher than in unmodified K562 cells, although the level was not as high as in cells that over-expressed miR-142
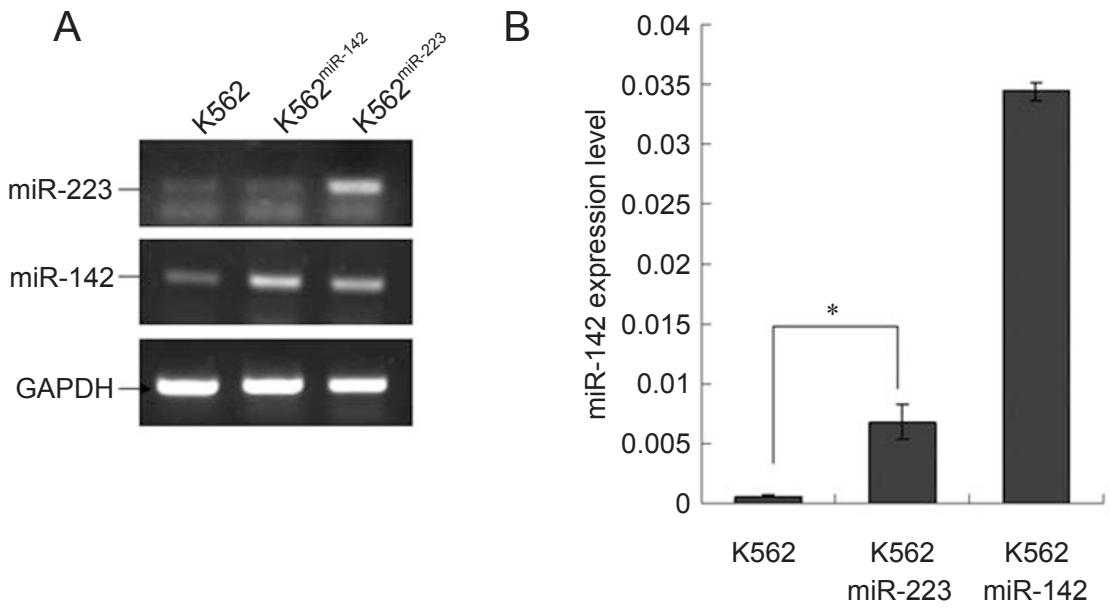

Figure 1 Over-expression of miR-223 in the myeloid cell line K562 caused up-regulation of miR-142. (A) Expression levels of miR-223 and miR-142 were shown by RT-PCR analysis in K562 cells and K562 cells that stably expressed miR-223 or miR-142 (K562 ${ }^{\text {miR-142 }}$ and $\mathrm{K} 562^{\text {miR-223 }}$ ). The housekeeping gene GAPDH was used as an internal control. (B) Real-time PCR detection of miR-142 expression levels in K562, K562 ${ }^{\text {miR-142 }}$ and $\mathrm{K} 562^{\mathrm{miR}-223}$ cells. The relative expression level of miR-142 was normalized to GAPDH. The bars represent the means of three independent experiments. * Student's $t$-test, $P<0.05$. 
(Figure 1A). The real-time PCR analysis showed exact fold changes of miR-142 expression in these three cell types (Figure 1B).

The transcription start site of the miR-142 primary transcript was identified by $5^{\prime} R A C E$ and the expression of miR-142 was down-regulated by $C E B P-\beta$

The data in Figure 1 showed a regulation of miR-142 expression by miR-223. However, until now, the transcription start site of miR-142 has not been confirmed. Using the 5' RACE protocol, a DNA fragment of about
300 bp was amplified from RNAs from K562 $2^{\text {miR-223 }}$ cells where miR-142 primary transcripts were relatively abundant (Figure 2A, sample lane). Interestingly, there was no specific band from the sample of K562 cells (Figure 2A, NC lane). The 300 bp DNA fragment was then cloned into the pMD-19T vector and sequenced. According to the alignment between the sequence of this fragment and the miR-142 genomic locus, the exact transcription start site was located $308 \mathrm{bp}$ upstream from the $5^{\prime}$ end of the miR-142 precursor (Figure 2B). On the other hand, a poly-A signal was also found about $730 \mathrm{bp}$ downstream

A $\underset{\text { miR-142 locus GCGGCCAGCCAGGGGTTCACAGAACTGAAGGTGAGGCCTCCAGAGGCCCTAGTCTCTACC }}{\longrightarrow+1 \text { transcription start site }}$ 5' RACE sequence CATGGGTTCACAGAACTGAAGGTGAGGCCTCCAGAGGCCCTAGTCTCTACC

C CCCACAAGGCCCAGGGCGGGCCCTCGGGGGGCCCTGGCAGGGTTGGGGGGATCTTAGGAA
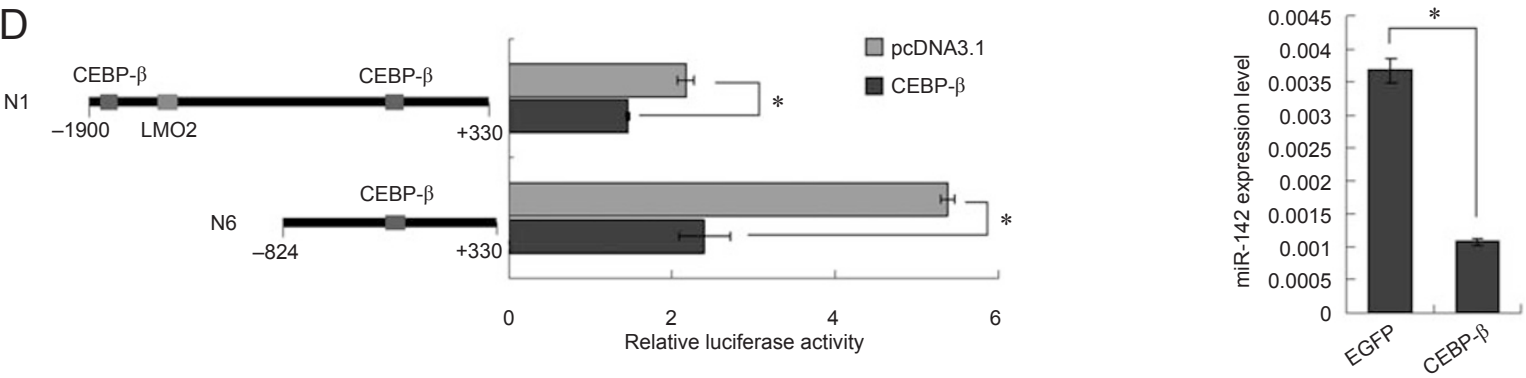

Figure2 Identification of transcription start site of miR-142 primary transcript and regulation of miR-142 expression by CEBP- $\beta$. (A) Nested PCR amplification result of miR-142 $5^{\prime}$ RACE. The band in the sample lane was amplified from a $\mathrm{K} 562^{\mathrm{miR}-223}$ cell sample, and the NC lane was derived from normal K562 cells and was used as the negative control to eliminate non-specific amplifications. (B) Sequence alignment of miR-142 5' RACE result and miR-142 genome locus. The result showed that the two sequences are identical, as noted in yellow; the transcription start site of the miR-142 primary transcript is also marked in the diagram. (C) The poly-A signal is located in the miR-142 locus about 750 bp downstream of the transcriptional start site. (D) Relative activity of the miR-142 promoter N1 and N6 and the down-regulation effect of CEBP- $\beta$ on them. The length and region of $\mathrm{N} 1$ and $\mathrm{N} 6$ and relative CEBP- $\beta$ and LMO2 binding sites are marked on the diagram; their relative Luciferase activity was normalized to Renilla luciferase activity. The graph shows the mean and standard error from at least three separate experiments. (E) Real-time PCR detection of endogenous miR-142 expression upon CEBP- $\beta$ overexpression in K562 cells. K562 cells over-expressing EGFP were used as a control. The relative expression level of miR142 was normalized by comparing to GAPDH. The bars represent the means from three independent experiments and three repeats for each experiment. * Student's $t$-test, $P<0.05$. 
of the transcription start site (Figure 2C) and this site was conserved in the corresponding location in the mouse genome (data not shown). These results indicate that the primary transcript of miR-142 is about $750 \mathrm{bp}$ in length, and that there are no introns in this gene.

In our previous study, it was demonstrated that LMO2 could negatively regulate the expression of miR-142 by binding to a typical LMO2 binding site located in the upstream region of the miR-142 locus [39]. In addition, the TESS online transcription element search system (http:// www.cbil.upenn.edu) revealed that there are two typical CEBP- $\beta$ sites in the $2 \mathrm{~kb}$ promoter region, as indicated in Figure 2D. However, Luciferase reporter assays showed that both reporters (N1, $2320 \mathrm{bp}$ in length and N6, 1154 $\mathrm{bp}$ in length) displayed reduced, rather than increased, activity when co-transfected with a CEBP- $\beta$ expression plasmid (full length CEBP- $\beta$ with the trans-activation domain at the N-terminus) in K562 cells (Figure 2D). Realtime PCR analysis showed that the endogenous miR-142 level was also decreased after transient over-expression of CEBP- $\beta$ in K562 cells (Figure 2E). It is widely accepted that the full-length form of CEBP- $\beta$ functions as a transcriptional activator, thus it seems unlikely that it could down-regulate the transcription of miR-142 directly. Therefore, the negative regulatory function on miR142 by the full-length form of CEBP- $\beta$ might be mediated by other factor(s).

The expression of CEBP- $\beta$ was down-regulated posttranscriptionally by miR-223

Directly or not, CEBP- $\beta$ was shown to be involved in the regulation of miR-142. Manual alignment showed that the core binding sequence of miR-223 (2-7 nt) matched well with the $3^{\prime}$ UTR sequence of CEBP- $\beta$ mRNA (Figure 3A). When the pGL3-control-CEBP- $\beta-3^{\prime}$ UTR reporter was co-transfected with the miR-223 expression vector into HEK293 cells, there was a $40 \%$ decrease in the Luciferase activity compared to the cells that were co-transfected with the reporter and the scrambled plasmid (Figure 3B). To further confirm this result,

A

Mature miR-223 sequence

CEBP- $\beta$ 3' UTR core

binding sequence

3'-CCCCAUAAACUGUUUGACUGU-5'

CEBP- $\beta$ 3' UTR mutant sequence

5'-AACGCGTGTGTACACGgGACTGACGCAAC-3'

5'-GGACACACG-3'

B

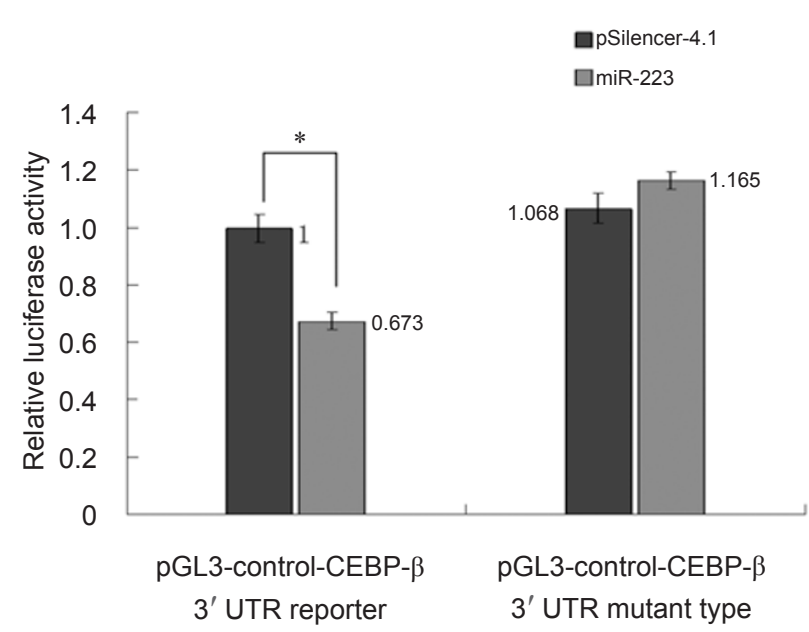

C

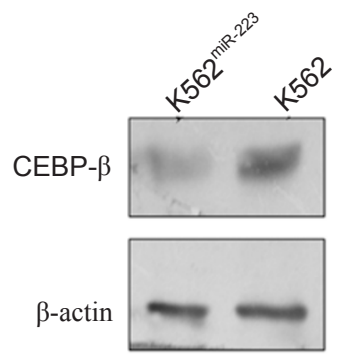

Figure 3 miR-223 down-regulated CEBP- $\beta$ in a post-transcriptional manner. (A) CEBP- $\beta$ mRNA 3' UTR targeted by miR223 and site mutation strategy. The core binding sequence (2-7 nt) between miR-223 and CEBP- $\beta$ 3' UTR matched well and TG in the middle of the core binding sequence was mutated to AC, as indicated. (B) Relative Luciferase activity of the pGL3control reporter bearing wild-type or mutated CEBP- $\beta$ mRNA 3' UTR with or without miR-223 co-expression in HEK293 cells. Luciferase activity was normalized by comparing to Renilla luciferase activity. The graph shows the mean and standard error from at least three separate experiments. * Student's $t$-test, $P<0.05$. (C) Western blot analysis of CEBP- $\beta$ expression in $\mathrm{K} 562$ and $\mathrm{K} 52^{\mathrm{miR}-223}$ cells. $\beta$-actin was used as an internal control. 
we generated pGL3-control-CEBP- $\beta$-3' UTR point mutant. After mutating the TG in core binding sequence to $\mathrm{AC}$, as shown in Figure $3 \mathrm{~A}$, the inhibition effect of miR-223 on this reporter was eliminated (Figure 3B). In addition, western blot analysis showed that the level of CEBP- $\beta$ protein was much lower in $\mathrm{K} 562^{\text {miR-223 }}$ cells than in unmodified K562 cells (Figure 3C). This result shows that CEBP- $\beta$ is a target of miR-223 and suggests an miR223 - CEBP- $\beta$ - miR-142 regulatory pathway.

miR-223 down-regulated both the LMO2-L and $-S$ isoforms transcriptionally and post-transcriptionally

Interestingly, when we examined the expression levels of the LMO2-L/-S isoforms, it was found that in $\mathrm{K} 562^{\text {miR-223 }}$ cells, the mRNA levels of both LMO2-L and $-\mathrm{S}$ decreased significantly (Figure 4A). Real-time PCR analysis showed that LMO2-L level decreased by about 5-fold while LMO2-S decreased by about 10-fold in $\mathrm{K} 562^{\text {miR-223 }}$ cells compared to unmodified K562 cells (Figure 4B). Notably, the Sanger miRNA database (http:// microrna.sanger.ac.uk) and the Targetscan online prediction program (http://www.targetscan.org) both show that LMO2 is a post-transcriptional target of miR-223 [16] (Figure 4C). As the 3' UTR in LMO2-L and LMO2-S mRNAs are identical, Luciferase reporter assays showed that miR-223 negatively regulated both the LMO2-L and the LMO2-S isoforms at a post-translational level (Figure 4D). Furthermore, in K562 cells transiently over-expressing $\mathrm{LMO} 2$, regardless of the isoform, we observed the decreased expression of miR-142. Accordingly, si-LMO2 showed the opposite effect (Figure 4E), suggesting that the up-regulation of miR-142 by miR-223 is mediated by LMO2.

$C E B P-\beta$ up-regulated the expression of both LMO2-L and $L M O 2-S$

Considering that miR-223 negatively regulated CEBP- $\beta$ directly in a post-transcriptional manner and down-regulated LMO2-L/-S at the transcriptional level, we sought to determine whether CEBP- $\beta$ mediated the transcriptional regulation from miR-223 to the LMO2 isoforms. To address this issue, the proximal promoter of LMO2-L (from -384 +119) and the promoter of $L M O 2-S$ (from -294 +332) were cloned from the normal human genome and inserted into a pGL4-based Luciferase reporter vector. In co-transfection assays with the CEBP- $\beta$ expression vector, both LMO2-L and -S promoter activities were increased significantly in the presence of CEBP- $\beta$ (Figure 5A). TESS online prediction program (http://www.cbil.upenn.edu) showed that there are one CEBP- $\beta$ binding site in LMO2-L proximal promoter and two in $\mathrm{LMO} 2-\mathrm{S}$ promoter (Figure $5 \mathrm{~B}$, core binding sequences are listed in the blue box). When the CEBP- $\beta$ site was mutated in the proximal promoter of LMO2-L (TA TTGC $\rightarrow$ TAGAGC), the CEBP- $\beta$-mediated up-regulation of the promoter's activity was eliminated. Similarly, mutation of either CEBP- $\beta$ site in the promoter of $L M O 2-S$ (TGATGGAAT $\rightarrow$ TGATGGGGT or

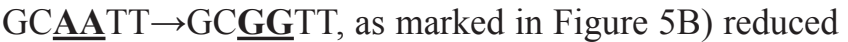
the CEBP- $\beta$-mediated activity of the promoter modestly, while mutation of both of these two sites eliminated this activity (Figure 5B). In chromatin immunoprecipitation (ChIP) assays using specific scanning primers (pLMO2-L primers and pLMO2-S primers), both of the promoters of $L M O 2-L$ and $L M O 2-S$ could be detected in the antiCEBP- $\beta$ precipitant (Figure $5 \mathrm{C}$ ). In addition, transient over-expression of CEBP- $\beta$ in the myeloid leukemia cell line U937 increased the mRNA levels of both LMO2-L and $-\mathrm{S}$, as detected by real-time PCR (Figure 5D). These data suggest that down-regulation of the LMO2 isoforms at the transcriptional level by miR-223 is mediated by CEBP- $\beta$, and LMO2 down-regulation further mediates miR-142 expression.

miR-223 and miR-142 similarly attenuated cell proliferation in the myeloid cell line K562

Some reports have indicated that miR-223 can affect cell growth in hematopoiesis $[12,15]$. According to the regulation pattern from miR-223 to miR-142 that we showed above, we hypothesized that the function of miR-223 might be achieved through miR-142. To address this issue, all K562 cells with modifications of miR-142 or miR-223 (K562 ${ }^{\text {miR-142 }}$ and $\mathrm{K} 562^{\text {miR-223 }}$ cells $)$, or the mediators involved in their regulation pathway $\left(\mathrm{K} 562^{\mathrm{si}-}\right.$ ${ }^{\mathrm{LMO} 2}, \mathrm{~K} 562^{\mathrm{LMO2}-\mathrm{L}}$, K562 $2^{\mathrm{LMO2}-\mathrm{S}}$ and K562 $2^{\mathrm{CEBP}-\beta}$ cells), were used for proliferation assays. Proliferation of the K562, $\mathrm{K} 562^{\text {miR-142 }}$ and $\mathrm{K} 562^{\mathrm{miR}-223}$ cells was first examined using the CCK8 assay. The cell number-absorbance standard curve of each cell type was established and then the absorbance of each sample was converted into cell number according to the standard curves. The graph in Figure 6A shows the growth curve of each cell type. It can be seen that $\mathrm{K} 562^{\text {miR-142 }}$ and $\mathrm{K} 562^{\text {miR-223 }}$ cells had decreased numbers of cells compared to unmodified K562 cells after a $48 \mathrm{~h}$ culture, and that this was more significant at $72 \mathrm{~h}$, indicating that proliferation was attenuated in $\mathrm{K}_{5} 62^{\mathrm{miR}-142}$ and K562 ${ }^{\text {miR-223 }}$ cells. Furthermore, BrdU incorportation assays were performed and analyzed by FACS. A statistically significant difference in the percentage of proliferating cells (BrdU/PI double-positive population) was observed in the $\mathrm{K} 562^{\mathrm{miR}-142}$ and $\mathrm{K} 562^{\mathrm{miR}-223}$ cells compared to the unmodified K562 cells. On average, this difference was $10 \%$. There was, however, almost no difference between the K562 ${ }^{\text {miR-142 }}$ and K562 ${ }^{\text {miR-223 }}$ cells (Figure 6B). In 
A

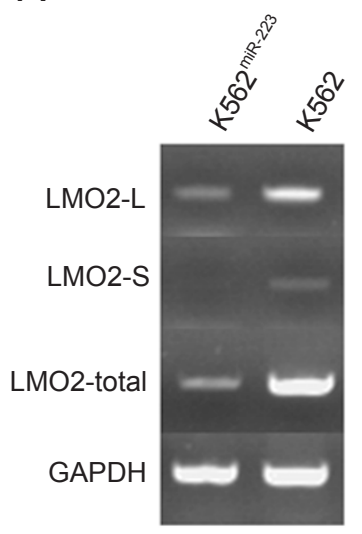

B

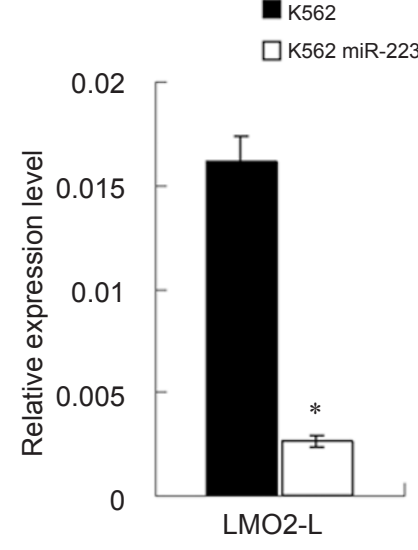

$\square \mathrm{K} 562$

$\square$ K562 miR-223

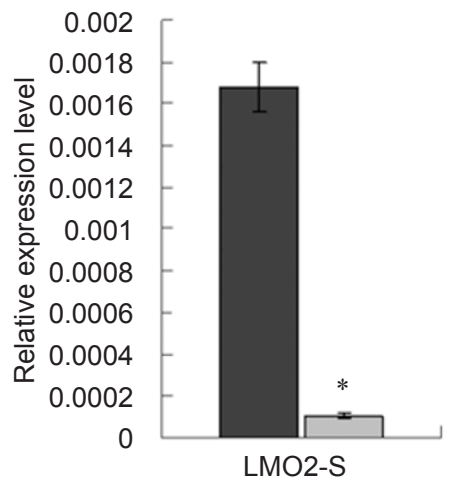

C
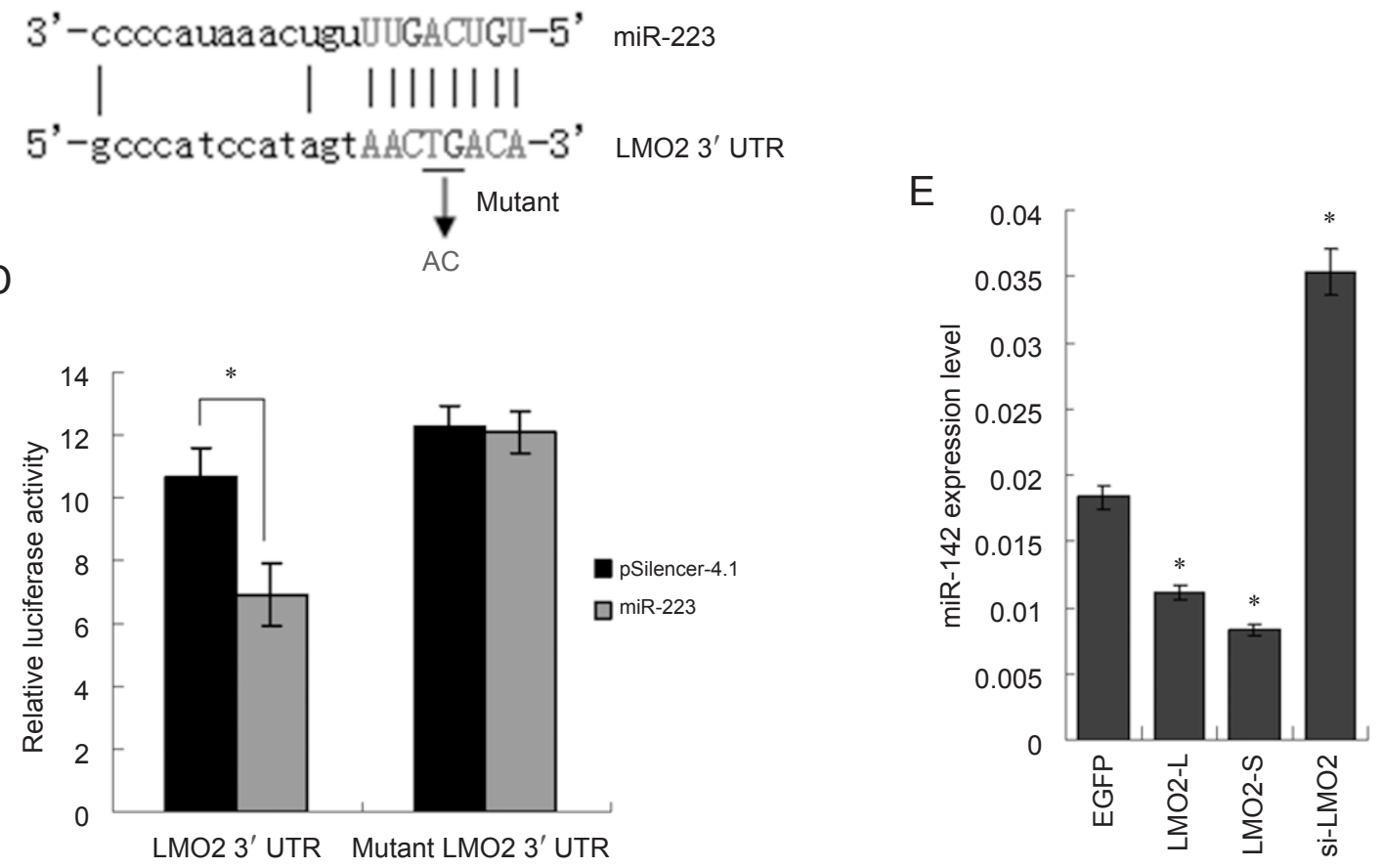

Figure 4 miR-223 down-regulated both LMO2-L and -S isoforms at a transcriptional and a post-transcriptional level. (A) mRNA levels of LMO2-L, LMO2-S and both (LMO2 total) as determined by RT-PCR analysis in K562 and K562 ${ }^{\mathrm{miR}-223}$ cells. The housekeeping gene GAPDH was used as a control. (B) Real-time PCR detection of LMO2-L and LMO2-S expression levels in K562 and K562 ${ }^{\text {miR-223 }}$ cells. The relative expression level of LMO2-L/-S was normalized by comparing to GAPDH. The bars represent the means of three independent experiments. * Student's $t$-test, $P<0.05$. (C) Diagram of LMO2-L/-S mRNA 3' UTR targeted by miR-223 and the site mutation strategy. TG in the middle of the core binding sequence was mutated to AC, as indicated. (D) Relative Luciferase activity of the pGL3-control reporter bearing wild-type or mutated LMO2-L/-S mRNA 3' UTR upon miR-223 co-expression in HEK293 cells. The relative Luciferase activity was normalized by comparing to Renilla luciferase activity. The graph shows the mean and standard error of the mean from at least three separate experiments. * Student's $t$-test, $P<0.05$. (E) Real-time PCR detection of endogenous miR-142 expression upon over-expression of LMO2-L, LMO2-S or si-LMO2 in K562 cells. K562 cells over-expressing EGFP were used as a control. The relative expression level of miR-142 was normalized by comparing to GAPDH. The bars represent the means from three independent experiments and three repeats for each experiment. * Student's $t$-test, $P<0.05$. 
A

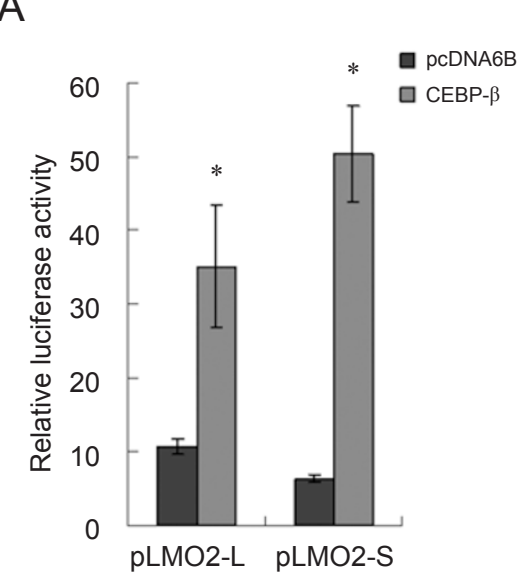

C

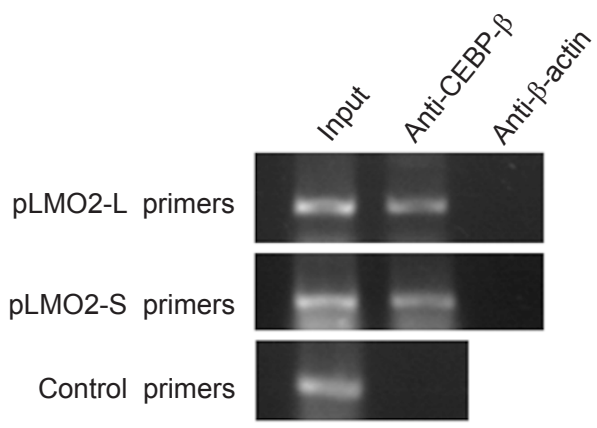

B

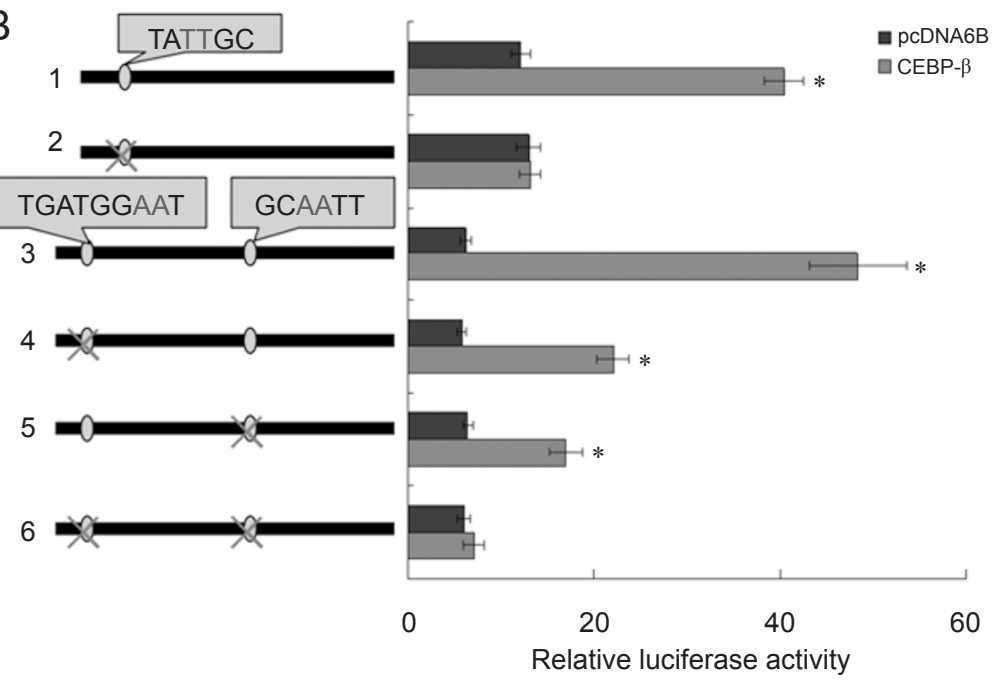

$\mathrm{D}$
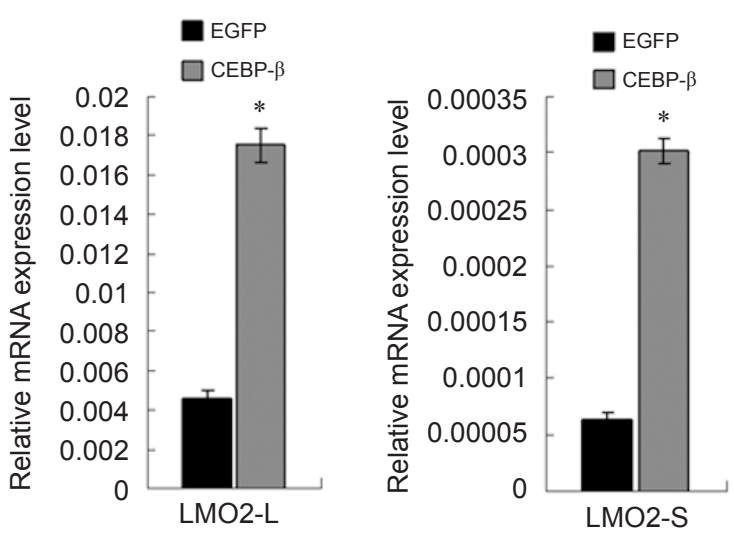

Figure 5 CEBP- $\beta$ up-regulated the expression of both LMO2-L and LMO2-S. (A) Promoter activities of the proximal promoter of LMO2-L (pLMO2-L) and LMO2-S (pLMO2-S) were up-regulated upon CEBP- $\beta$ co-expression. (B) Mutation strategies for the proximal LMO2-L promoter and LMO2-S promoter and their relative promoter activities. The dot represents the CEBP- $\beta$ binding site in the region and relative DNA sequences are indicated in the blue window. $\times$ indicates a mutation site. 1,2 , LMO2-L proximal promoter. 3-6, LMO2-S promoter. * Student's $t$-test, $P<0.05$. (C) ChIP assay showed that CEBP- $\beta$ associates with endogenous LMO2-L proximal and LMO2-S promoter in the myeloid cell line K562. pLMO2-L primers were specific for scanning the LMO2-L proximal promoter region while pLMO2-S primers were specific for the LMO2-S promoter region. Control primers were used to amplify a region $15 \mathrm{~kb}$ away from from the LMO2-L proximal promoter to eliminate pseudopositive results. Concentrated cell lysates (Input) was used as a positive control while sample of $\beta$-actin antibody immunoprecipitating group was used as negative control. (D) Real-time PCR detection of endogenous LMO2-L and LMO2-S expression upon over-expression of CEBP- $\beta$ in U937 cells. Cells over-expressing EGFP were used as a control. The relative expression level of LMO2-L/-S was normalized by comparing to GAPDH. The bars represent the means from three independent experiments. * Student's $t$-test, $P<0.05$.

addition, the proliferation status of $\mathrm{K} 562^{\text {si-LMO2 }}, \mathrm{K} 562^{\mathrm{LMO} 2-}$ ${ }^{\mathrm{L}}, \mathrm{K} 562^{\mathrm{LMO2-S}}$ and $\mathrm{K} 562^{\mathrm{CEBP}-\beta}$ cells was also examined. We showed earlier that LMO2-L, LMO2-S and CEBP- $\beta$ could down-regulate miR-142 levels while si-LMO2 could up-regulate miR-142 levels. Accordingly, the percentage of cells undergoing proliferation in K562 cells was about $5 \%$ less than in the control (unmodified K562 cells and K562 cells transfected with pcDNA6B empty vector) and was similar to that in $\mathrm{K} 562^{\mathrm{miR}-142}$ and K562 ${ }^{\text {miR-223 }}$ cells. However, the percentage of cells undergoing proliferation increased $(\geq 5 \%)$ in $\mathrm{K} 562^{\mathrm{LMO2}-\mathrm{L}}$, $\mathrm{K} 562^{\mathrm{LMO2}-\mathrm{S}}$ and $\mathrm{K} 562^{\mathrm{CEBP}-\beta}$ cells compared to the control (Figure 6B). Figure 6C shows representative FACS results of each of the cell types. There were obvious nonproliferating subgroups (BrdU negative, PI positive) in $\mathrm{K} 562^{\mathrm{miR}-142}, \mathrm{~K} 562^{\text {miR-223 }}$ and $\mathrm{K} 562^{\text {si-LMO2 }}$ cells compared to 

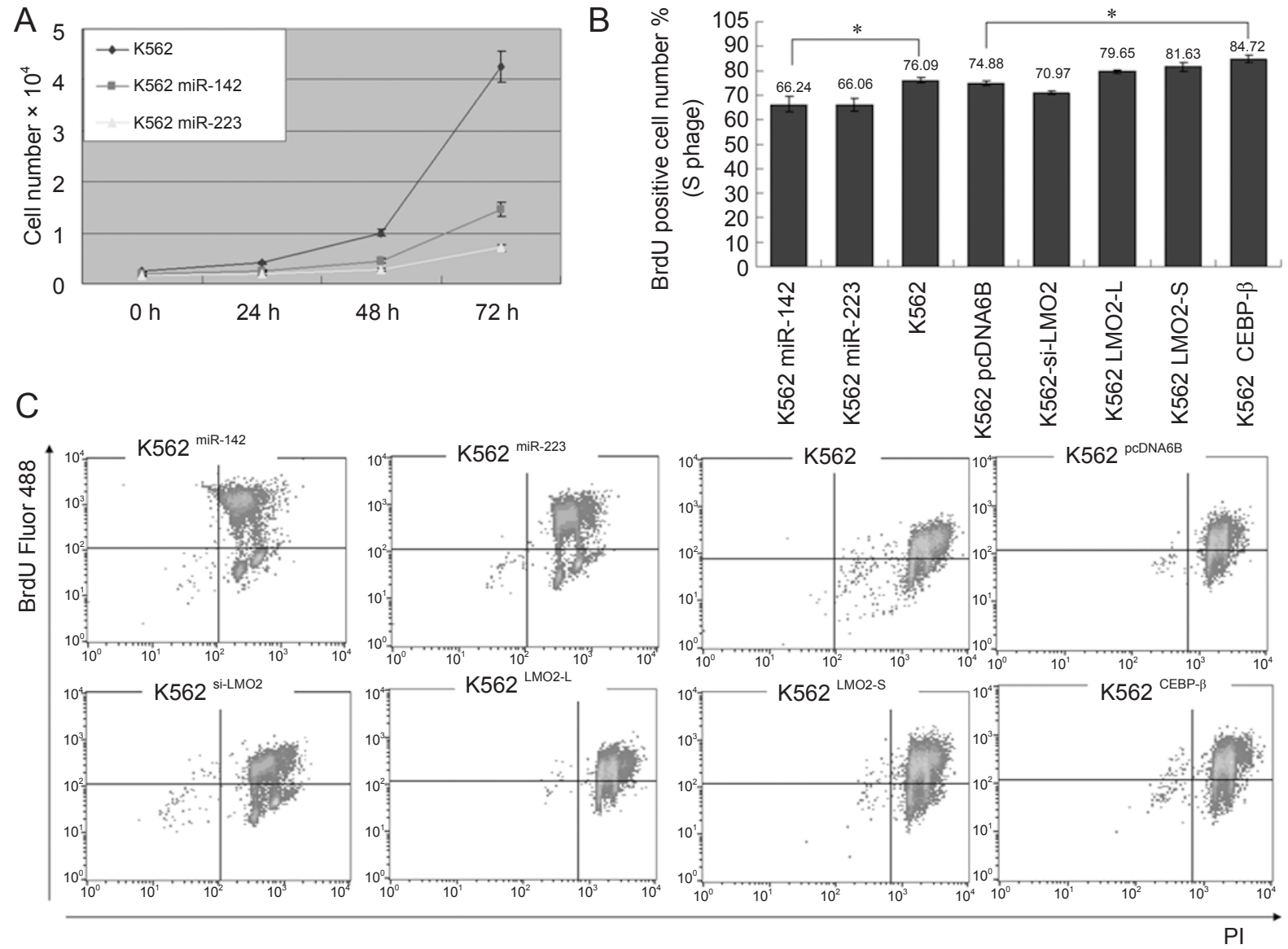

Figure 6. miR-223 and miR-142 had similarly decreased cell proliferation in the myeloid cell line K562. (A) CCK-8 cell proliferation assay of K562, K562 $2^{\text {miR-142 }}$ and $\mathrm{K} 562^{\text {miR-223 }}$ cells. The cell number-absorbance standard curve of each cell line was first established. Then, the absorbance of each sample was converted into cell number according to the standard curves. The graph shows the cell number-time growth curve of each cell line. Each sample was examined in quadruplicate. (B) Percentage of PI/BrdU double-positive cells for each cell strain by FACS analysis. The bars represent the means from three independent experiments. * Student's $t$-test, $P<0.05$. (C) Representative FACS analysis of each cell line, as indicated. The $x$-axis indicates $\mathrm{PI}$ while the $\mathrm{y}$-axis indicates anti-BrdU conjugated Flour-488.

other cells. All of the results suggest that both miR-223 and miR-142 attenuate hematopoietic cell proliferation and that miR-223 achieves this function by up-regulating miR-142.

\section{Discussion}

Increasing evidence shows that microRNAs are involved in controlling hematopoiesis. Considering the mechanism of miRNA regulation, they should function indirectly in this process through inhibiting the expression of their targets. There have been some reports of the functions of miRNAs and their related target genes in hematopoiesis, such as kit regulation by miR-221 and -222 in erythrocyte development [40], and HOXA1 regu- lation by $\mathrm{miR}-10 \mathrm{a}$ and MAFB regulation by miR-130a in megakaryocyte development [41]. As suggested by some reports, each miRNA has several targets [42]. Some of the targets may be crucial transcriptional regulators, such as CEBP- $\beta$ and LMO2. Thus, changes in miRNA expression might cause a cascade of gene expression changes that could in turn affect hematopoiesis. Some miRNAs may also be involved in the regulatory network as the indirect regulatory targets of other miRNAs: the regulation of miR-142 by miR-223 is such an example, suggesting that expression of microRNAs can also be regulated by other microRNAs.

miR-223 and miR-142 were initially reported to have a similar function in promoting T-cell development [12]. Interestingly, the expression of miR-223 in the T-cell lin- 
eage is barely detectable, while the expression of miR142 is somewhat detectable in all hematopoietic lineages [43]. miR-223 is abundantly expressed in myeloid cells, and until now, all revealed targets of miR-223 were those involved in myeloid cell development, including NFI-A [13], LMO2-L/-S isoforms and CEBP- $\beta$ (reported herein). Our data here revealed an miR-223-CEBP- $\beta$ LMO2 - miR-142 regulatory pathway and a functional relationship between miR-223 and miR-142 in attenuating cell proliferation (Figure 7). The regulatory pathway from miR-223 to miR-142 is composed of several branches including LMO2-L/-S isoforms and CEBP- $\beta$. It seems complicated and redundant, but achieves a precise regulation, and the redundancy may render the pathway robust and resistant to slight fluctuations in the cellular environment.

Notably, among all these factors, LMO2 occupies in the core position of this pathway, as it directly and solely controls miR-142 expression. LMO2 was considered as an oncogene because its ectopic expression in hematopoietic cells caused T-cell leukemia [29, 30]. It can be inferred that during hematopoiesis, the miR223 - CEBP- $\beta$ - LMO2 - miR-142 regulatory pathway mainly functions to control cell proliferation, which is helpful for normal cell differentiation and development. If LMO2 is ectopically expressed, however, it breaks the equilibrium in this pathway, which can not be compensated for by its upstream regulatory factors. Ectopically expressed LMO2 ultimately targets miR-142 and downregulates its expression, accelerating cell proliferation

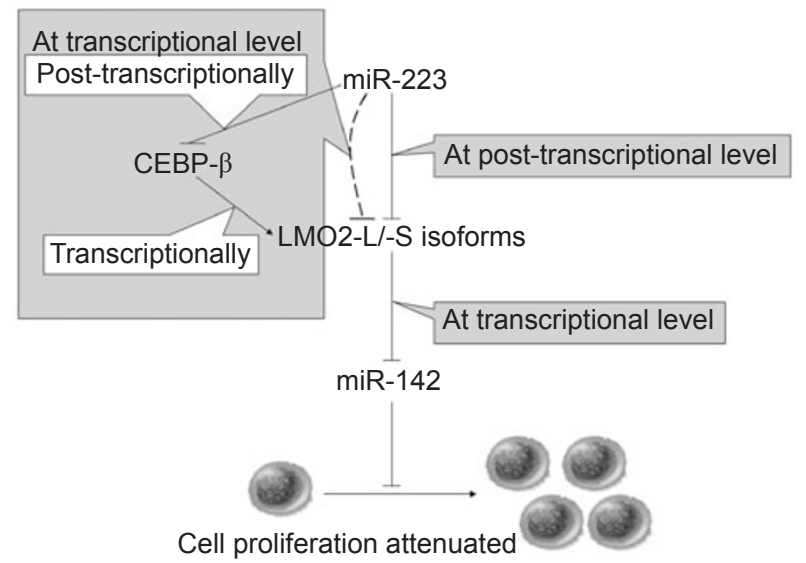

Figure 7 Diagram of the regulation pattern from miR-223 to miR-142. miR-223 negatively regulates LMO2-L/-S isoforms post-transcriptionally and transcriptionally. The transcriptional regulation was mediated by CEBP- $\beta$, as shown in the blue box. LMO2 negatively regulates miR-142 in a transcriptional manner and miR-142 achieves the ultimate function of attenuating cell proliferation. and increasing the risk for leukemia. Taken together, our data embed LMO2 in a novel regulation pathway of hematopoiesis, and suggest that the oncogenic property of LMO2 might be achieved by accelerating cell proliferation through repressing miR-142.

\section{Materials and Methods}

\section{Plasmid construct}

The proximal promoter region of $L m o 2-L$ (from $-384 \sim+119$ ) and promoter region of LMO2-S (from -294 +332) were cloned from normal human genome, inserted into the pGL4-basic vector and confirmed by sequencing. The $3^{\prime}$ UTR of LMO2 and CEBP- $\beta$ were cloned from human peripheral blood cDNA, sequenced and inserted into the pGL3-control vector at the $X b a$ I site. LMO2$\mathrm{L}, \mathrm{LMO} 2-\mathrm{S}$ and CEBP- $\beta$ expression vectors were constructed by amplification of their relevant coding sequences from human peripheral blood cDNA and inserting into pcDNA3.1(+) vector. miR-142 and miR-223 expression sequences were cloned from human peripheral blood cDNA. The length of these fragments was as previously reported [12]. Such fragments were inserted into the pSilencer4.1-CMV neo vector (Ambion, CA, USA) and confirmed by sequencing. Primers used for cloning are supplied as Supplementary Information, Table S3. si-LMO2-L/-S construct was generated as follows: DNA templates for siRNA targeting to human LMO2-L/-S mRNAs were synthesized and cloned into $\mathrm{pSi}$ lencer 4.1-CMV neo vector (Ambion). The target sequence of the siRNAs was 5'-TCA GGG GTT TTC TTC CCC T-3'.

\section{Cell culture and transfection}

K562 and U937 cells were cultured in RPMI 1640 medium supplemented with $10 \%$ fetal bovine serum (GIBCO BRL, Grand Island, NY, USA), $100 \mu \mathrm{g} / \mathrm{ml}$ penicillin and $100 \mu \mathrm{g} / \mathrm{ml}$ streptomycin. HEK293 cells were cultured in DMEM with $10 \%$ fetal bovine serum (GIBCO), $100 \mu \mathrm{g} / \mathrm{ml}$ penicillin and $100 \mu \mathrm{g} / \mathrm{ml}$ streptomycin. Electroporation of K562 and U937 cells was performed as follows: $2 \times 10^{6} \mathrm{~K} 562 / \mathrm{U} 937$ cells were resuspended in $200 \mu \mathrm{l}$ RPMI 1640 medium without serum or antibiotics, and mixed with $10 \mu \mathrm{g}$ total plasmid DNA. Electroporation was performed with Gene Pulser (Bio-Rad, Hercules, CA, USA) using the following parameters: exponential wave, $210 \mathrm{~V}, 950 \mu \mathrm{F}, 4 \mathrm{~mm}$ cassette.

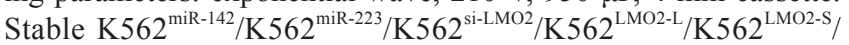
K562 ${ }^{\text {CEBP- } \beta}$ cell types were generated by G418 selection: K562 cells were transfected with relative expression vector by electroporation. The transfected cells were resuspended in RPMI 1640 medium with $400 \mu \mathrm{g} / \mathrm{ml} \mathrm{G} 41824 \mathrm{~h}$ after electroporation and cultured for 30 days. The expression of miR-142/miR-223 was confirmed by RT-PCR. HEK293 cells for transfection were plated at $1 \times 10^{5}$ cells/well in 24-well plates and transfected by Lipofectamine 2000 according to the manufacturer's instructions (Invitrogen, Austin, TX, USA).

\section{RNA isolation, RT-PCR and real-time PCR}

Total RNA was isolated from cells using Trizol reagent (Invitrogen). $1.5 \mu \mathrm{g}$ of each sample was used for reverse transcription by M-MLV (Promega, Madison, WI, USA), followed by PCR and real-time PCR detection. Real-time PCR was performed with the ABI PRISM 7000 (ABI, USA), using $1 \times$ Evagreen dye and ROX 
as a passive reference. The amplification parameters were $95^{\circ} \mathrm{C}$ for $3 \mathrm{~min}$ followed by 40 cycles of $95{ }^{\circ} \mathrm{C}$ for $30 \mathrm{~s}$ and $64{ }^{\circ} \mathrm{C}$ for $1 \mathrm{~min}$. Primers used for detection are supplied as Supplementary Information, Table S2. The relevant gene expression levels were normalized by fold change relative to the housekeeping gene GAPDH.

\section{Western blot analysis}

Cells were lysed by mRIPA (50 mmol/L Tris- $\mathrm{HCl} \mathrm{pH} 7.5,150$ $\mathrm{mmol} / \mathrm{L} \mathrm{NaCl}, 1 \%$ Triton X-100, 0.5\% DOC, $10 \mu \mathrm{g} / \mathrm{mL}$ Aprotinin, $10 \mu \mathrm{g} / \mathrm{mL}$ Leupeptin, $1 \mathrm{mmol} / \mathrm{L}$ PMSF). Total protein concentration was measured with the BCA Protein Assay Kit (Pierce Biotechnology, Rockford, IL, USA). A total of $60 \mu \mathrm{g}$ of each sample was subjected to SDS-PAGE. After fractionation, the proteins were transferred to a nitrocellulose membrane, and they were detected using an anti-CEBP- $\beta$ polyclonal antibody (Santa Cruz, CA, USA). Immunostaining was detected using an enhanced chemiluminescence system (Amersham Pharmacia Biotech, Buckinghamshire, UK).

\section{Luciferase assay}

Co-transfection into HEK293 cells of the pGL3-controlLMO2 3' UTR or the pGL3-control-CEBP- $\beta$ 3' UTR with the pSilencer4.1-neo vector or the pSilencer4.1-miR-223 expression vector occurred at a ratio of $1: 2$, and the ratio between the Luciferase reporter and Renilla was 5:1. The ratio between the LMO2-L or LMO2-S promoter reporter and the CEBP- $\beta$ expression vector was 1:1 for the co-transfection into HEK293 cells. The ratio between the 142 Luciferase reporter, the CEBP- $\beta$ expression vector and Renilla was 5:5:1 in a total of $10 \mu \mathrm{g}$ for electroporation of K562 cells. Cells were lysed $24 \mathrm{~h}$ after transfection. The Luciferase activity was measured using the Dual-Luciferase Reporter Assay Kit (Promega) and normalized to the Renilla luciferase activity, according to the manufacturer's instructions.

\section{Site-directed mutation}

Mutation of relevant sites in the pGL3-control-LMO2/CEBP- $\beta$ 3' UTR and pGL4-LMO2-L/S promoter was performed using the Stratagene QuikChange Site-Directed Mutagenesis Kit (Stratagene, La Jolla, CA, USA) following the manufacturer's instructions. The primers used to generate the mutations are supplied in the Supplementary Information, Table S1. Efficient mutations were confirmed by sequencing.

\section{5'-Full RACE}

Total RNA from K562 cells stably expressing miR-223 was extracted using Trizol reagent (Invitrogen). $2 \mu \mathrm{g}$ RNA was then used for 5'-RACE with the TaKaRa 5'-Full RACE Kit (TaKaRa, Dalian, China). Total RNAs were first treated with Calf Intestine Phosphatase (CIP) to remove the 5' phosphate of non-capped RNAs, then a decap procedure was performed for the $5^{\prime}$ full length capped mRNAs, producing a $5^{\prime}$ phosphate on these RNAs. Next, ligation with RACE adaptor (a kit component) was performed to allow the $5^{\prime}$ full length mRNAs to be ligated. These samples were then reverse-transcribed by M-MLV (Promega) and used as template for nested PCR in which the inner and outer forward primers (kit components) were matched with the adaptor and reverse primers designed specifically according to the pre-miR-142 sequence.
The parameters for the first round of PCR were $95{ }^{\circ} \mathrm{C}$ for $30 \mathrm{~s}, 55$ ${ }^{\circ} \mathrm{C}$ for $30 \mathrm{~s}, 72{ }^{\circ} \mathrm{C}$ for $4 \mathrm{~min}, 20$ cycles and for the second round of PCR were $95{ }^{\circ} \mathrm{C}$ for $30 \mathrm{~s}, 65{ }^{\circ} \mathrm{C}$ for $30 \mathrm{~s}, 72{ }^{\circ} \mathrm{C}$ for $4 \mathrm{~min}, 35$ cycles. Specific downstream primers for RACE are listed in the Supplementary Information, Table S5. The PCR product was cloned into the pMD19-T vector (TaKaRa) and sequenced.

\section{Chromosome immunoprecipitation (ChIP) assay}

$3 \times 10^{6} \mathrm{~K} 562$ cells were harvested for a ChIP assay using the Millipore Chromosome Immunoprecipitation Assay Kit (Millipore, Billerica, MA, USA). A total of $1 \times 10^{6}$ cells was lysed with 100 $\mu \mathrm{L}$ SDS Lysis Buffer (a kit component), sonicated at $40 \mathrm{~W}, 10 \mathrm{~s}$ each time for 6 times. These samples were diluted in 10 times their volume of Dilution Buffer (a kit component). After pre-clearing with protein $\mathrm{G}$ beads ( $75 \mu \mathrm{L}$ per sample), the samples were incubated with the anti-CEBP- $\beta$ antibody or the anti- $\beta$-actin antibody as negative a control at $4{ }^{\circ} \mathrm{C}$ over night with rotation, and then incubated with protein $\mathrm{G}$ beads $(60 \mu \mathrm{L}$ per sample) for $1 \mathrm{~h}$. After stringent washing with Low Salt, High Salt, $\mathrm{LiCl}$ and TE buffers (kit components), the DNA fragments that bound to the protein $\mathrm{G}$ beads were eluted with Elution Buffer containing 0.1 $\mathrm{M} \mathrm{NaHCO}_{3}$ and $1 \%$ SDS. These samples as well as the cell lysates used as inputs were concentrated and used as the templates for PCR analysis. Primers used for detection are listed in the Supplementary information, Table S4. The PCR amplification parameters were $95^{\circ} \mathrm{C}$ for $3 \mathrm{~min}$, followed by $95^{\circ} \mathrm{C}$ for $30 \mathrm{~s}, 58^{\circ} \mathrm{C}$ for $30 \mathrm{~s}$ and $72{ }^{\circ} \mathrm{C}$ for $45 \mathrm{~s}, 35$ cycles.

\section{CCK-8 cell proliferation assay}

The assay was performed using the DOJINDO Cell Counting Kit-8 (DOJINDO, Gathersburg, Maryland, USA) according to the manufacturer's instructions. K562, K562 $2^{\text {miR-142 }}$ and K562 ${ }^{\text {miR-223 }}$ cells were first cultured in a series of known quantities $\left(1 \times 10^{3}-1.6\right.$ $\times 10^{4}$ in 2 fold linear) in 96-well plates and used for establishing their absorbance-cell number standard curves. Then, the cells were cultured in normal medium and the absorbance at $450 \mathrm{~nm}$ was determined every $24 \mathrm{~h}$. The total number of each kind of cell was calculated according to the standard curve.

\section{BrdU incorporation labeled cell proliferation assay}

All cells used for this assay were cultured in a density of about $5 \times 10^{5} / \mathrm{ml}$, and BrdU (Sigma, St Louis, USA) in a final concentration of $10 \mu \mathrm{mol} / \mathrm{L}$ was added into the medium $1 \mathrm{~h}$ before harvest of cells. Collected cells were washed by PBS twice and fixed with $75 \%$ ethanol at $-20^{\circ} \mathrm{C}$ for $24 \mathrm{~h}$. Fixed cells were then treated with 2 $\mathrm{M} \mathrm{HCL}$ for $30 \mathrm{~min}$ and $0.1 \mathrm{M} \mathrm{Na}_{2} \mathrm{~B}_{4} \mathrm{O}_{7}$ for $2 \mathrm{~min}$ at room temperature. The anti-BrdU monoclonal antibody (Santa Cruz) was diluted in Washing Solution (PBS supplied with $0.5 \%$ BSA) in a ratio of 1:200 and incubated with cell samples for $1.5 \mathrm{~h}$. After washing, the samples were incubated with the Flour 488-conjugated anti-mouse IgG antibody (Invitrogen) (1:200 dilution in Washing Solution) for $1 \mathrm{~h}$. These samples were then washed and stained with PI (final concentration $50 \mu \mathrm{g} / \mathrm{ml}$ with $20 \mu \mathrm{g} / \mathrm{ml}$ RNaseA) and analyzed by a two-gated flow cytometer.

\section{Acknowledgment}

This work was supported by the National Natural Science Foundation of China (Grant No. 30771054). 


\section{References}

1 Yu J, Wang F, Yang GH, et al. Human microRNA clusters: Genomic organization and expression profile in leukemia cell lines. Biochem Biophys Res Commun 2006; 349:59-68.

2 Lee Y, Kim M, Han J, et al. MicroRNA genes are transcribed by RNA polymerase II. EMBO J 2004; 23:4051-4060.

3 Cai X, Hagedorn CH, Cullen BR. Human micro-RNAs are processed from capped, polyadenylated transcripts that can also function as mRNAs. RNA 2004; 10:1957-1966.

4 Lee Y, Ahn C, Han J, et al. The nuclear RNase III Drosha initiates microRNA processing. Nature 2003; 425:415-419.

5 Denli AM, Tops BB, Plasterk RH, Ketting RF, Hannon GJ. Processing of primary microRNAs by the Microprocessor complex. Nature 2004; 432:231-235.

6 Lund E, Guttinger S, Calado A, Dahlberg JE, Kutay U. Nuclear export of microRNA precursors. Science 2004; 303:9598.

7 Yi R, Qin Y, Macara IG, Cullen BR. Exportin-5 mediates the nuclear export of pre-microRNAs and short hairpin RNAs. Genes Dev 2003; 17:3011-3016.

8 Grishok A, Pasquinelli AE, Conte D, et al. Genes and mechanisms related to RNA interference regulate expression of the small temporal RNAs that control C. elegans developmental timing. Cell 2001; 106:23-34.

9 Hutvagner G, McLachlan J, Pasquinelli AE, Balint E, Tuschl $\mathrm{T}$, Zamore PD. A cellular function for the RNA-interference enzyme Dicer in the maturation of the let-7 small temporal RNA. Science 2001; 293:834-838.

10 Doench JG, Sharp PA. Specificity of microRNA target selection in translational repression. Genes Dev 2004; 18:504-511.

11 Shivdasani RA. MicroRNAs: regulators of gene expression and cell differentiation. Blood 2006; 108:3646-3653.

12 Chen CZ, Li L, Lodish HF, Bartel DP. MicroRNAs modulate hematopoietic lineage differentiation. Science 2004; 303:8386.

13 Fazi F, Rosa A, Fatica A, et al. A minicircuitry comprised of microRNA-223 and transcription factors NFI-A and C/EBPalpha regulates human granulopoiesis. Cell 2005; 123:819-831.

14 Fazi F, Racanicchi S, Zardo G, et al. Epigenetic silencing of the myelopoiesis regulator microRNA-223 by the AML1/ ETO oncoprotein. Cancer Cell 2007; 12:457-466.

15 Johnnidis JB, Harris MH, Wheeler RT, et al. Regulation of progenitor cell proliferation and granulocyte function by microRNA-223. Nature 2008; 451:1125-1129.

16 Yuan JY, Wang F, Yu J, Yang GH, Liu XL, Zhang JW. MicroRNA-223 reversibly regulates erythroid and megakaryocytic differentiation of K562 cells. J Cell Mol Med 2008; 13:4551-4559.

17 Fukao T, Fukuda Y, Kiga K, et al. An evolutionarily conserved mechanism for microRNA-223 expression revealed by microRNA gene profiling. Cell 2007; 129:617-631.

18 Lekstrom-Himes J, Xanthopoulos KG. Biological role of the CCAAT/enhancer-binding protein family of transcription factors. J Biol Chem 1998; 273:28545-28548.

19 Xie H, Ye M, Feng R, Graf T. Stepwise reprogramming of B cells into macrophages. Cell 2004; 117:663-676.

20 Laiosa CV, Stadtfeld M, Xie H, Andres-Aguayo L, Graf T. Reprogramming of committed $\mathrm{T}$ cell progenitors to mac- rophages and dendritic cells by C/EBPa and PU.1 transcription factors. Immunity 2006; 25:731-744.

21 Royer-Pokora B, Loos Uschi, Ludwig WD, et al. TTG-2 a new gene encoding a cysteine-rich protein with LIM motif, is overexpressed in acute T-cell leukaemia with the $\mathrm{t}(11 ; 14)$ (p13;q11). Oncogene 1991; 6:1887-1893.

22 Aplan PD, Lombardi DP, Reaman GH, Sather HN, Hammond GD, Kirsch IR. Involvement of the putative hematopoietic transcription factor SCL in T-cell acute lymphoblastic leukemia. Blood 1992; 79:1327-1333.

23 Ferrando AA, Neuberg DS, Staunton J, et al. Gene expression signatures define novel oncogenic pathways in $\mathrm{T}$ cell acute lymphoblastic leukemia. Cancer Cell 2002; 1:75-87.

24 Ferrando AA, Herblot S, Palomero T, et al. Biallelic transcriptional activation of oncogenic transcription factors in T-cell acute lymphoblastic leukemia. Blood 2004; 103:1909-1911.

25 Pike-Overzet K, de Ridder D, Weerkamp F, et al. Ectopic retroviral expression of LMO2, but not IL2Rc, blocks human T-cell development. Leukemia 2007; 21:754-763.

26 Yamada Y, Warren AJ, Dobson C, et al. The T cell leukemia LIM protein Lmo2 is necessary for adult mouse hematopoiesis. Proc Natl Acad Sci USA 1998; 95:3890-3895.

27 Yamada Y, Pannell R, Forster A, et al. The oncogenic LIMonly transcription factor Lmo2 regulates angiogenesis but not vasculogenesis in mice. Proc Natl Acad Sci USA 2000; 97:320-324.

28 Warren AJ, Colledge WH, Carlton MB, et al. The oncogenic cysteine-rich LIM domain protein rbtn2 is essential for erythroid development. Cell 1994; 78:45-57.

29 Larson RC, Fisch P, Larson TA, et al. T cell tumours with disparate phenotype in mice transgenic for Rbtn-2. Oncogene 1994; 9:3675-3681.

30 Hacein-Bey-Abina S, Von Kalle C, Schmidt M, et al. LMO2associated clonal $\mathrm{T}$ cell proliferation in two patients after gene therapy for SCID-X1. Science 2003; 302:415-419.

31 McCormack MP, Forster A, Drynan L, Pannell R, Rabbitts TH. The LMO2 T-cell oncogene is activated via chromosomal translocations or retroviral insertion during gene therapy but has no mandatory role in normal T-cell development. Mol Cell Biol 2003; 23:9003-9013.

32 Royer-Pokora B, Rogers M, Zhu TH, et al. the TTG-2/RBTN$2 \mathrm{~T}$ cell oncogene encodes two alternative transcripts form two promoter: the distal promoter is removed by most $11 \mathrm{p} 13$ translocations in acute T cell leukemia's (T-ALL). Oncogene 1995; 10:1353-1360.

33 Zhu T, Qin G, Royer-Pokora B. A novel post-transcriptional splicing form of the acute $\mathrm{T}$ cell leukemia proto-oncogene Lmo2. Sci China C Life Sci 2001; 44:561-569.

34 Hammond SM, Crable SC, Anderson KP. Negative regulatory elements are present in the human LMO2 oncogene and may contribute to its expression in leukemia. Leuk Res 2005; 29:89-97.

35 Landry JR, Kinston S, Knezevic K, Donaldson IJ, Green AR, Göttgens B. Fli1, Elf1, and Ets1 regulate the proximal promoter of the LMO2 gene in endothelial cells. Blood 2005; 106:2680-2687.

36 Wang Q, Zhang $\mathrm{M}$, Wang $\mathrm{X}$, et al. A novel transcript of the LMO2 gene, LMO2-c, is regulated by GATA-1 and PU.1 and encodes an antagonist of LMO2. Leukemia 2007; 21:1015- 
1025.

37 Wadman I A, Osada H, Grutz G, et al. The LIM-only protein Lmo2 is a bridging molecule assembling an erythroid, DNAbinding complex which includes the TAL1, E47, GATA-1 and Ldb1/NLI proteins. EMBO J 1997; 16:3145-3157.

38 Nam CH, Rabbitts TH. The role of LMO2 in development and in T cell leukemia after chromosomal translocation or retroviral insertion. Mol Ther 2006; 13:15-25.

39 Yuan W, Sun W, Yang S, et al. Down-regulation of microRNA-142 by proto-oncogene LMO2 and its co-factors. Leukemia 2008; 22:1067-1071.

40 Felli N, Fontana L, Pelosi E, et al. MicroRNAs 221 and 222 inhibit normal erythropoiesis and erythroleukemic cell growth via kit receptor down-modulation. Proc Natl Acad Sci USA 2005; 102:18081-18086.

41 Garzon R, Pichiorri F, Palumbo T, et al. MicroRNA fingerprints during human megakaryocytopoiesis. Proc Natl Acad Sci USA 2006; 103:5078-5083.

42 Karginov FV, Conaco C, Xuan Z, et al. A biochemical approach to identifying microRNA targets. Proc Natl Acad Sci USA 2007; 104:19291-19296.

43 Ramkissoon SH, Mainwaring LA, Ogasawara Y, et al. Hematopoietic-specific microRNA expression in human cells. Leuk Res 2006; 30:643-647.

(Supplementary information is linked to the online version of the paper on the Cell Research website.) 